\title{
A Novel Strategy for Designing and Manufacturing a Fixed Wing MAV for the Purpose of Increasing Maneuverability and Stability in Longitudinal Axis
}

\author{
M. Radmanesh ${ }^{1 \dagger}$, O. Nematollahi ${ }^{1}$,M. Nili-Ahmadabadi ${ }^{1}$ and M. Hassanalian ${ }^{1}$ \\ ${ }^{1}$ Department of Mechanical Engineering, Isfahan University of Technology, Isfahan 84156-83111, Iran \\ †Corresponding Author Email: Rezaradmanesh90@hotmail.com
}

\begin{abstract}
In this study, a novel simple strategy is proposed to choose and accommodate an airfoil based on the effects of airfoil type and plan-form shape on the flight performance of a micro air vehicle. In this strategy, after defining flight mission, the weight of the micro air vehicle is estimated and then, aerodynamic parameters and thrust force are calculated. In the next step, some different plan-forms and airfoils are investigated to be selected for decreasing the stall region in high attack anglesby open source software named XFLR5. Having calculated the aerodynamic center, the pitching moment needed to stabilize the micro air vehicle is computed. Due to the static margin, the airfoil camber line is changed to stabilize the micro air vehicle and then, its thickness is improved to reach to a high aerodynamic characteristic. To evaluate the software results, some flight tests are performed which then compared to the software results that show a good agreement. Finally, some adjustments and improvements are made on the micro air vehicle and then, its performance is obtained by the flight tests. The flight test results show it has an excellent aerodynamic performance, stability and maneuverability.
\end{abstract}

Keywords: Airfoil, Design Strategy, MAV, Plan-form, Stability, Maneuverability.

\section{NOMENCLATURE}

$\begin{array}{cl}C & \text { reference chord } \\ C_{l w} & \text { lift coefficient generated by the vehicle wing } \\ C_{l h} & \text { tail lift coefficient } \\ C_{m c g b} & \text { pitching moment around foil center of mass } \\ C_{m a c w} & \begin{array}{l}\text { wing pitching coefficient around the } \\ \text { aerodynamic center of gravity }\end{array} \\ C_{D} & \text { lift drag coefficient equals zero } \\ h & \text { flight height } \\ K_{l} & \text { polar second-order coefficient } \\ K_{2} & \text { polar first-order coefficient } \\ & \text { distance between center of gravity and } \\ L_{h} & \text { aerodynamic center of tail } \\ n & \text { lift to vehicle weight in various flight phases } \\ & \text { dynamic pressure }\end{array}$

\section{INTRODUCTION}

Micro air vehicles (MAVs) are very significant due to their application in civil, military and industry along with their low weight asaspecific
$S_{h} \quad$ horizontal tail area

$S_{W} \quad$ wing area

$T_{S L} \quad$ trust at sea level while taking off

$W_{T O}$ total weight of air vehicle at takeoff

$W_{\text {STR }} \quad$ air vehicle structure weight

$W_{P L} \quad$ weight of air vehicle pay load

$W_{B} \quad$ battery weight

$W_{P P} \quad$ propulsion weight of air vehicle

$X_{c g}$ the distance between aerodynamic center and the center of gravity

$\alpha \quad$ trust constant in different flight phases

$\beta \quad$ weight ratio in different flight phases

$\Lambda_{C / 4}$ sweep angle of air vehicle in 0.25 length of chord

characteristic. They are unmanned and their sizes are less than 1 meter. According to a defined mission,MAV size with its mounted equipments can vary. Their small sizes compared with the other unmanned air vehicles (UAV) causes the MAVs to 
have an extensive operation field. Although their small sizes reduce the structure costs, the related electronic equipments are very expensive. Also, they are of high sensitivity in design and performance because of their small sizes. On the other hand, airfoil design and optimization is very important in aerodynamics because of its significant role in flight. Therefore, the body of MAV are completely composed of airfoil to have a better performance Barnhart et al. (2004).

However, MAVs can be categorized into fixed wings, quad rotors, flapping and vertical flier kinds as shown in Fig. 1. They flight like other unmanned air vehicles by remote control because the human attendance is difficult, dangerous or even impossible. With regard to the mentioned specifications, MAVshave a series of potentials for performing some missions like detecting andpatrolling. The first research on MAVs was performed in RAND institution. At that work, some multiple studies were done on MAVssmaller than 5 $\mathrm{cm}$ which areable to perform detecting and rescuing missions Torres and Mueller (2004).

Because MAVs are very small-size and low speed TheirReynolds number are very low that results unique aerodynamic conditions (Zhang, 2007 ). On the other hand, the limited wing surface causes the generated lift force to be low. Plan-forms, the top view of MAVs, are in the form of Delta, Zimmerman, Inverse Zimmerman, Rectangular, Elliptical and irregular ones Anderson, (2009) Some different plan-forms are shown in Fig. 2. Aerodynamic optimization of plan-forms increases the aspect ratio of air vehicle incorrectly and impractically (Obayashi, 1998 ) In classic planes, the shape of plan-form should be selected in the preliminary steps (Obayashi, 2000 ) Because design methods are aimed at improving specific conditions of air vehicle plane, and the proposed design plan can be adapted to other design cycles, some parts arebriefly mentioned beforehand.

The first flight was performed by Wright brothers in 1903 (Liebeck, 2004 ; Corning, 1953 )explained the conceptual design of ultrasound and infrasound passenger air vehicles. The order he used in his air vehicle design was considered as one of the first design documents. Having introduced the amphibious air vehicles, Wood clarified their basics which were the preliminary discussion in this field (Wood, 1968 ; Stinton, 1998 )described the basics of airscrews and their condition.( Nicolai, 1975 ) introduced mass estimation in conceptual design of air combats and ultrasound air vehicles. He is one of the introducers of the economic effects on the air vehicle design. (Roskam, 1985 )suggested a new design procedure in which various variables including aerodynamic, foil, flight dynamic and run force were considered separately.(Whitford, 1987 ) analyzed different design procedures of air combats. He evaluated effective variables in air combat performance from the First World War.(Torenbeek, 1982 ) investigated the experimental relations of design and suggested a method to calculate the air vehicle mass.(Raymer, 2012 ) proposed a method to increase the air vehicle maneuverability and decrease the drag force in ultrasound flight using the computational fluid dynamic and finite elements.(Anderson, 2009) evaluated the relations between the air vehicles design and their performance.

The time and energy used in design and examination of air vehicle are very important. Airfoil selection is an important stage of design and has a rigorous effect on the vehicle performance. In MAV design procedure, the aim is to neglect the horizontal tail because, the lower the construction weight, the higher the MAV performance. The massive structures need to have more effective wing span. The aim of MAV construction is to reduce size and weight of air vehicle.

In this research, a procedure is presented to select the MAV airfoil shape without horizontal tail and to study all parameters of airfoil selection. Also, Using the proposed procedure, a vast range of airfoils are evaluated in such a way that the time required for the design and flight tests reduces. In this methodlike the most design procedures, the trial and flight tests are key components. Having computed the air vehicle weight, it is necessary that the most fitted plan-form be selected for the defined mission. In this paper, a fixed wing MAV would be designed using the proposed method.

Different methods have been developed in order to ease the path for designers to asset the needed airplane. The novelty of theproposed strategy lies within the difference of airfoil selection and optimization for mission requerimientos.The mission requerimientoscould be summarized in the amounts of maneuverability, stability and endurance of MAV in different flight conditions. Each of these has an impact on the flight and also could change the type and size of airfoil. Reformation of airfoil is one of theadvantages of this method to maximizethe performance of the tailless MAV. Changing the airfoil shape and evaluating the aerodynamic characteristics of the changed shape byusing open source software named XFLR5 give designersinsight intoairfoil selection and design. None of the mentioned strategies discussesthe evaluation, optimization and improvisation ofairfoil for air vehicles requirements.

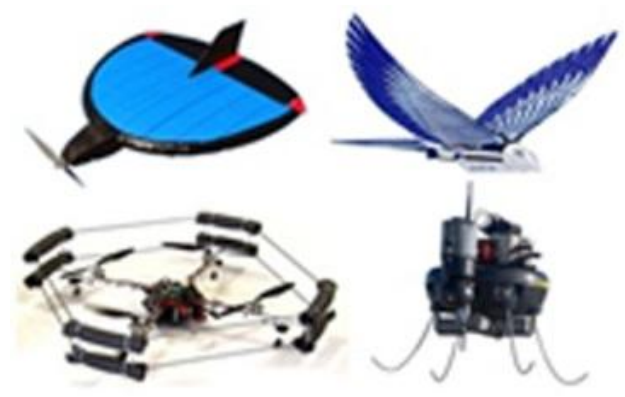

Fig. 1. samples of MAVs 


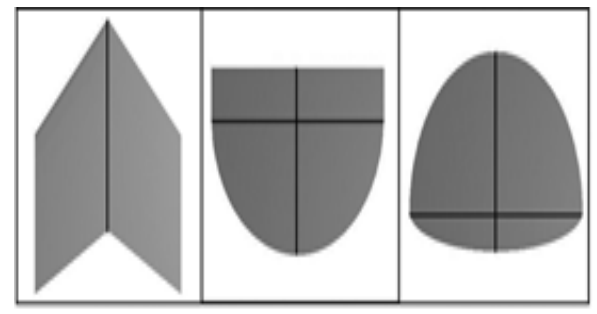

Fig. 2. Samples of Plan-forms

\section{XFLR5}

XFLR5 is open source software which analyzes the aerodynamic characteristics of $3 \mathrm{D}$ geometries. As a matter of fact, it is the advanced version of XFoil software. This software has multiple abilities such as airfoil analysis; planning and drawing wing, foil, tail and the other components. Therefore, it can be used for the aerodynamic analysis and stability control (Deperrois, 2010). In XFLR5, air vehicle is evaluated using one of the three following methods:

$$
\begin{aligned}
& \text { a. } \\
& \text { b. } \\
& \text { c. }
\end{aligned}
$$

Each mentioned method has its own limitation and preferences. Each wing is defined by multiple panels described with the following parameters:

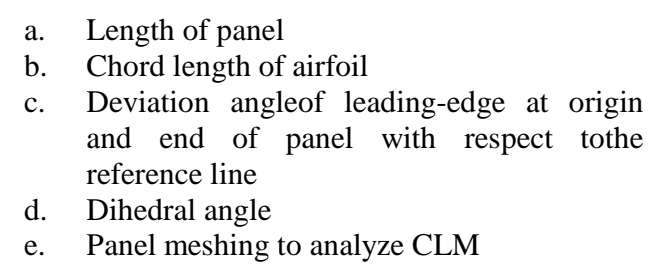

\section{DESIGN METHODOLOGY}

As mentioned before, in order to start designing, it is necessary that mission be defined. The mission that the MAV is run into is very important. In other words, the mission represents the loads MAV needs and specifies the mission endurance. Therefore, some weights of the equipments would be varying according to the mission.

Having defined the mission, the MAV weight can be estimated according to the loads induced on it (Gallman, 1993). The results of numerous researches show that the weight must be analyzed to find the form and size of plan-forms (..Wakayama, 1995). One way to weight estimation is statistical methods in which the weight is estimated according to the equation between the body and takeoff weight. Using the statistical data and plotting different profiles, it seems there is a linear equation between $\log \left(\mathrm{W}_{\text {str }}\right)$ and $\log \left(\mathrm{W}_{\mathrm{TO}}\right)$ of air vehicle. Having weight data of similar air vehicles, drawing the log profiles and calculating takeoff weight in terms of structure weight, a linear equation is concluded as follows.

$$
\begin{aligned}
& W_{T O}=W_{s t r}+W_{P P}+W_{P L}+W_{B} \\
& W_{s t r}=x W_{T O}
\end{aligned}
$$

Regarding to the statistical population, Fig.4 has been drawn.

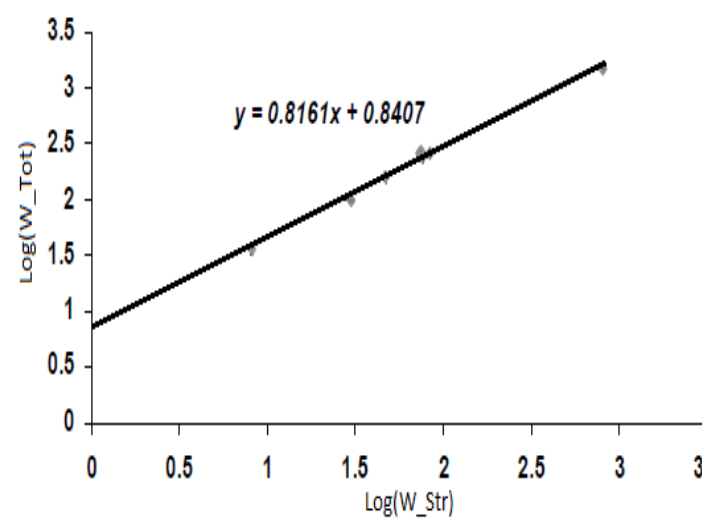

Fig. 4. Statistical diagram for $\left(\log \left(\mathbf{W} \_S t r\right)\right.$ vs. $\log \left(\mathbf{W}_{-}\right.$Tot $\left.)\right)$

Therefore, for total weight estimation, the $\mathrm{x}$ valueshould be calculated. Weight of equipments is estimated 300 grams. Also, according to the above profile and database, the structure weight to total weight ratio is estimated 0.33 . Considering the fact that the total weight of structure and equipments is the only unknown parameter, its value is estimated 450gr as below:

$$
\begin{aligned}
& \mathrm{W}_{\mathrm{B}}=120 \mathrm{~g}, \\
& \mathrm{~W}_{\mathrm{PL}}: 140 \mathrm{~g}, \\
& \mathrm{~W}_{\mathrm{PP}}=110 \mathrm{~g},
\end{aligned}
$$

The structure weight is $130 \mathrm{gr}$ of which $20 \mathrm{gr}$ is considered as the margin error.

\section{CONSTRAINS ANALYSIS FOR MAV}

Forces on a flying MAV including lift, drag, thrust and weight. In this MAV,the drag and thrust forces are in the same lines, with opposite direction. In Fig. 5, the forces on a MAV are shown.

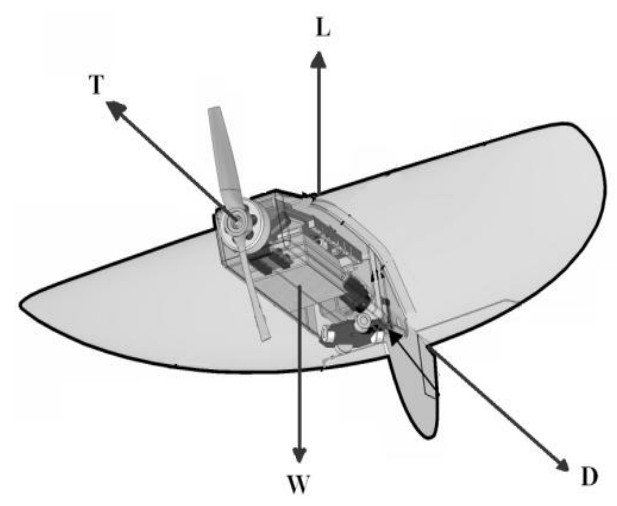

Fig. 5. Forces on MAV 
Writing the energy balance equation for MAV, the constraint equation of MAV would be gained.

$$
\begin{aligned}
& \frac{T_{S L}}{W_{T O}}=\frac{\beta}{\alpha}\left\{\frac { q S } { \beta W _ { T O } } \left[K_{1}\left(\frac{n \beta}{q} \frac{W_{T O}}{S}\right)^{2}\right.\right. \\
& \left.\left.+K_{2}\left(\frac{n \beta}{q} \frac{W_{T O}}{S}\right)+C_{D_{0}}\right]+\frac{1}{V} \frac{d}{d t}\left[h+\frac{V^{2}}{2 g}\right]\right\}
\end{aligned}
$$

The above equation relates the aircraft's wing loading to the thrust one. Eq. (3) would be used for different flight modes. For MAVs with electric motor, simulation is in the form of thrust due to total weight $\left(\mathrm{T}_{\mathrm{SL}} / \mathrm{W}_{\mathrm{TO}}\right)$ on the total wing loading $\left(\mathrm{W}_{\mathrm{TO}} / \mathrm{S}\right)$. In the following equation $\mathrm{R}_{\mathrm{C}}=$ Radius around, $\mathrm{dh} / \mathrm{dt}=$ Ascent velocity, $\mathrm{dv} / \mathrm{dt}=$ Accelerationand $\mathrm{C}_{\mathrm{Lmax}}=$ Maximum lift coefficient.

State 1: Constant altitude/speed cruise, $P_{S}=0$

$$
\frac{T_{S L}}{W}=\frac{1}{\alpha}\left[\left(\frac{1}{\pi e A R}\right) \frac{2}{\rho V^{2}}\left(\frac{W}{S}\right)+\frac{C_{D O}}{\frac{2}{\rho V^{2}}\left(\frac{W}{S}\right)}\right]
$$

State 2: Constant speed climb, $\mathrm{P}_{\mathrm{S}}=\mathrm{dh} / \mathrm{dt}$

$$
\frac{T_{S L}}{W}=\frac{1}{\alpha}\left[\left(\frac{1}{\pi e A R}\right) \frac{1}{q}\left(\frac{W}{S}\right)+\frac{C_{D O}}{\frac{1}{q}\left(\frac{W}{S}\right)}+\frac{1}{V} \frac{d h}{d t}\right]
$$

State 3: Constant altitude/speed turn, $\mathrm{P}_{\mathrm{S}}=0$

$$
\frac{T_{S L}}{W}=\frac{1}{\alpha}\left[\begin{array}{l}
\frac{1}{\pi e A R}\left(1+\left(\frac{V^{2}}{g R_{C}}\right)\right) \frac{2}{\rho V^{2}}\left(\frac{W}{S}\right) \\
+\frac{C_{D O}}{\frac{2}{\rho V^{2}}\left(\frac{W}{S}\right)}
\end{array}\right]
$$

$$
\frac{T_{S L}}{W}=\frac{\beta}{\alpha}\left[\frac{1}{\pi e A R} \frac{1}{q}\left(\frac{W}{S}\right)+\frac{C_{D O}}{\frac{1}{q}\left(\frac{W}{S}\right)}+\frac{1}{g} \frac{d V}{d t}\right]
$$

State 5: Accelerated climb, $P_{S}=d h / d t+V d V / g d t$

$$
\frac{T_{S L}}{W}=\frac{1}{\alpha}\left\{\begin{array}{l}
\frac{q s}{W}\left[\frac{1}{\pi e A R}\left(\frac{1}{q} \frac{W}{S}\right)^{2}+C_{D 0}\right] \\
+\frac{1}{V} \frac{d}{d t}\left(h+\frac{V^{2}}{2 g}\right)
\end{array}\right\}
$$

State 6: Hand launching

$$
\frac{T_{S L}}{W}=\frac{1}{\alpha}\left[\frac{1}{\pi e A R} C_{L \max }+\frac{C_{D o}}{C_{L \max }}\right]
$$

With performance constraint analysis and plotting relevant graphs, ultimately, solution space forMAV design point is determined. In Fig. 6, the presented graph is a constraint analysis ofMAVperformed by (Hassanalian, 2012 ).

Having performed analysis and estimated trust force, the wing area can be calculated according the followingequation.

$$
\frac{T_{S L}}{W_{T O}}=0.65\left(\mathrm{~m}^{2}\right)
$$

Pay Load $=\frac{W_{T O}}{S}=35\left(N / m^{2}\right)$

State 4: Horizontal acceleration, $\mathrm{P}_{\mathrm{S}}=\mathrm{V} / \mathrm{g} \mathrm{dV} / \mathrm{dt}$

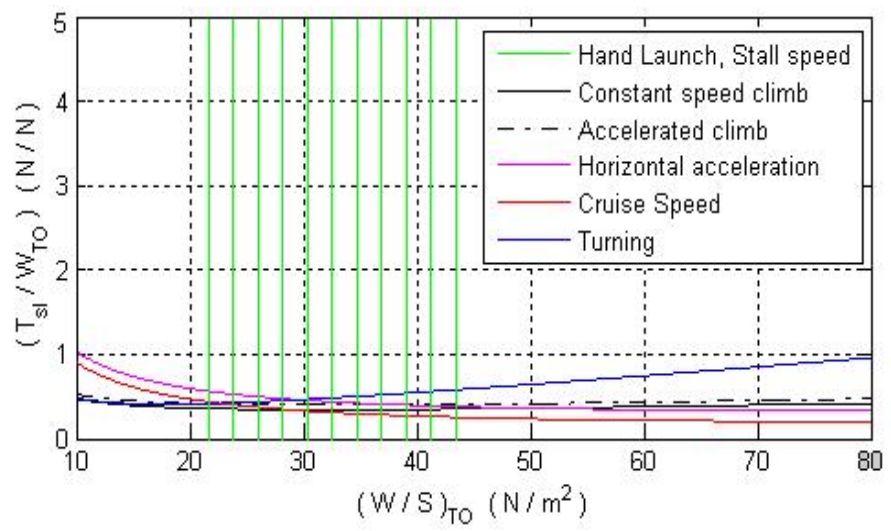

Fig .6 Constraint analyses for a MAV 
Here, some standard plan-forms such as Rectangular, Zimmerman, Inverse Zimmerman, Elliptical, Delta and Morphing are investigated to be considered as our selection.Afterwards, the results of these plan-forms are analyzed using XFLR5 software. The software is validated by comparison between the software results and wind tunnel experimental data. The main aim of this phase is to investigate different plan-forms shapes; therefore, it is necessary that the other parameters be constant. So, the plan-form area and length and, theairfoil type should not be changed. The following parameters are computed from the software to be compared to each other.
a) Higher lift coefficient
b) Higher aerodynamic ratio
c) Higher $\mathrm{C}_{\mathrm{Lmax}}$ and $\alpha \mathrm{C}_{\mathrm{Lmax}}$
d) More distance from the leading edge to separation boundary
e) ability to build selective plan-form

Some results of S5020 airfoil obtained from the software are mentioned in Table1 in which $\mathrm{C}_{\mathrm{L}}$ obtained from zero attack angle .It is evident the differences between $\mathrm{C}_{\mathrm{L}}$ in different plan-forms are more rigorous at higher attack angles.For the above analyses, the sweep back angle for Delta and Inverse Zimmerman plan-forms is assumed 25 degrees to create the best condition for MAV (Mattingly, 2002 ) Also, for MAV with Plan-form1, the sweep back angle is11-12 degrees. The cruise speed is selected 20 $\mathrm{m} / \mathrm{s}$ based on which Reynolds number is obtained 520000. Considering $\mathrm{m}=450 \mathrm{gr}$, air density $=1.225$ $\mathrm{kg} / \mathrm{m}^{3}$ and airfoil aspect ratio $=1.5$, the wing area is obtained $12.6 \mathrm{dcm}^{2}$. The plan-form shape with its sizes is shown in Fig.7.

\section{Table 1 Plan form performances in the same} conditions

\begin{tabular}{|l|c|c|c|c|}
\hline Plan form & $\mathrm{C}_{\mathrm{L}}$ & $\mathrm{L} / \mathrm{D}$ & $\mathrm{C}_{\mathrm{L}_{\max }}$ & $\alpha_{\mathrm{C}_{\mathrm{L}_{\max }}}$ \\
\hline Zimmerman & 0.035 & 3.45 & 1.19 & $55-65$ \\
\hline Inv. Zimmerman & 0.038 & 3.64 & 1.19 & $55-65$ \\
\hline Rectangular & 0.034 & 3.31 & 1.21 & $55-65$ \\
\hline Elliptical & 0.035 & 3.36 & 1.18 & $55-65$ \\
\hline $\begin{array}{l}\text { Delta } \\
\text { MAV Plan- } \\
\text { form1 }\end{array}$ & 0.034 & 3.35 & 1.19 & $55-65$ \\
\hline
\end{tabular}

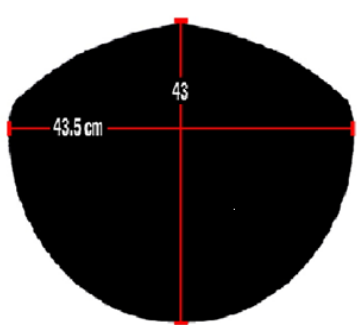

Fig. 7. Plan-form that used for designing the MAV

The MAV Plan-form 1 is a modified versionof inverse Zimmerman plan-form which was designed by Isfahan University of Technology design team.

Now, it is time to choose the appropriate airfoil. Having specified all aerodynamic parameters, the airfoil type can be chosen to meet the prescribed aerodynamic specifications. In cruise speed, the equation is:

$m g=L=\frac{1}{2} \rho v^{2} S C_{L}$

Minimum value of 3D lift coefficient calculated from the above equationis 0.143 . Therefore, the selective airfoil must satisfythe lift coefficient. All analysis is performed atangle of attack of 4 degrees. The investigated airfoils are showed in Table 2.

Table 2 Airfoil tested for the vehicle

\begin{tabular}{|c|c|c|}
\hline Airfoils & Lift Coefficient & Pitching moment \\
\hline mh81 & 0.689 & -0.009 \\
\hline s5020 & 0.592 & -0.003 \\
\hline s5010 & 0.58 & -0.004 \\
\hline goe744 & 0.814 & -0.017 \\
\hline fx05h126 & 0.746 & -0.039 \\
\hline ah80136 & 0.628 & -0.01 \\
\hline mh104 & 0.612 & -0.011 \\
\hline B29tip & 0.683 & -0.035 \\
\hline E169 & 0.443 & 0.003 \\
\hline
\end{tabular}

Because of large and non-negligible errors caused by designing equations, introduced by Radmanesh et al. (2012),in order to select the airfoils meeting desirable lift coefficient, the flowchart shownin Fig. 8 is used.Another phenomenon of low Reynolds number is flow separation bubble. Flow separation bubble is seen when flowdispatches from the wing surface near the leading edgeand free shear layer is formed in 
laminar flow. If the Reynolds number exceeds a critical value, the air vehicle will encounter an unsteady condition. Little turbulences of the flow lead to turbulent flow in the free shear layer. This free turbulent shear layer causes the flow to be attachedthe wing surface again. The width of the flow separation bubble is varied between $15 \%$ and $40 \%$ of airfoil chord line (Mueller 2003). Regarding the mentioned issues, the airfoils work efficiently, if flow separation bubble does not occur

Next step is to find the aerodynamic center on the plan-form. Aerodynamic center is a point located on the plan-form surface around which the lift force moments are zero. The aerodynamic center is estimated for each plan-form related to lift coefficient in low attack angle by using linear regression for gradient of the pitching moment profile (Recktenwald, 2010 ). Generally, pitching moment is calculated around $25 \%$ of chord line fromthe leading-edge. It isoften a negative value (Crook, 2002 )

$\mathrm{C}_{\mathrm{m}}=\frac{2 \mathrm{M}}{\rho \mathrm{CSV}^{2}}$

If the longitudinal stability of air vehicle is supposed to be investigated, it is necessary to calculate the pitching moment around the center of gravity of air vehicle according to Eq. (14).

$$
\begin{aligned}
\mathrm{C}_{\mathrm{mcg}} & =\frac{\mathrm{x}_{\mathrm{cg}}}{\overline{\mathrm{C}}} \mathrm{C}_{\mathrm{lw}}-\frac{\mathrm{l}_{\mathrm{h}} \mathrm{S}_{\mathrm{h}}}{\overline{\overline{\mathrm{C}}} \mathrm{S}_{\mathrm{w}}} \mathrm{C}_{\mathrm{lh}} \\
& +\mathrm{C}_{\text {macw }}+\mathrm{C}_{\text {mcgbody }}
\end{aligned}
$$

The pitching moment variation related to the attack angle is called the pitching stiffness $\left(C_{m \alpha}\right)$. The pitching moment variation versus thewing lift coefficient is defined by Eq. (15).

$$
\begin{aligned}
& \frac{\partial \mathrm{C}_{\text {mcg }}}{\partial \alpha}=\frac{\mathrm{x}_{\mathrm{cg}}}{\overline{\mathrm{C}}} \mathrm{C}_{\mathrm{l} \alpha \mathrm{W}}-\frac{\mathrm{l}_{\mathrm{h}} \mathrm{S}_{\mathrm{h}}}{\overline{\mathrm{C}} \mathrm{S}_{\mathrm{W}}} \mathrm{C}_{\mathrm{l} \alpha \mathrm{h}} \\
& +\frac{\partial \mathrm{C}_{\text {megbody }}}{\partial \alpha}
\end{aligned}
$$

The role of horizontal tail for stabilizing theair vehicle is symbolically shown in Fig. 9.

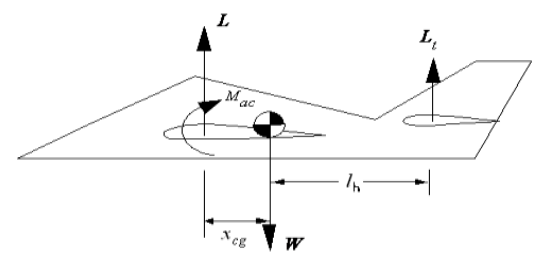

Fig. 9. Longitudinal stability of airplane

For MAVs, the equations are simplifiedas follows:

$M=M_{0}-x($ Lift $)$

$c_{m}=c_{m_{0}}-\frac{x}{l} c_{l}$

The Static Margin is defined as below equation:

$\frac{\partial C_{m c g}}{\partial C_{l}}=-\frac{x}{M A C} \times 100=-$ Static Margin

Therefore, for fixed-wing MAVs without horizontal tail, two scales related to pitching moment are obtained. These parameters are given in Eq. (12). and (13).

$c_{m_{0}}>0$

$\frac{\partial \mathrm{C}_{\mathrm{mcg}}}{\partial c_{l}}<0$

With regard to the behavior of $\mathrm{C}_{1}$ profiles against $\alpha$, it is founded that these two parameters are directly related before the airfoil reaches stall. So, it is concluded that:

$\frac{\partial \mathrm{C}_{\mathrm{mcg}}}{\partial \alpha}<0$

Therefore,if the static margin isobtained, the distance between AC and CG can be calculated. To achieve $\mathrm{C}_{\mathrm{m}}$ for3D air vehicle, the cruise state is considered. In this situation,the below equations are obtained writing static equationsfor air vehicle.

$W . x=M_{3 D}$

$\frac{2 W}{\rho C S V^{2}} \cdot x=C_{m c g}$

Having considered the plan-form,the Static margin is selected $10 \%$. Therefore, according to Eq. (16), the distance between the gravity center and aerodynamic center is $3.8 \mathrm{~cm}$. It means that the center of gravity is located $4.166 \mathrm{~cm}$ away from the plan form tip. Thus, according to Eq. (21), 3D moment coefficient is 0.0143.To calculate $\mathrm{C}_{\mathrm{mw}}$, the following equation is used, briefly:

$\mathrm{C}_{\mathrm{mcg}}=\mathrm{C}_{l}(x)+\mathrm{C}_{\mathrm{mw}}$

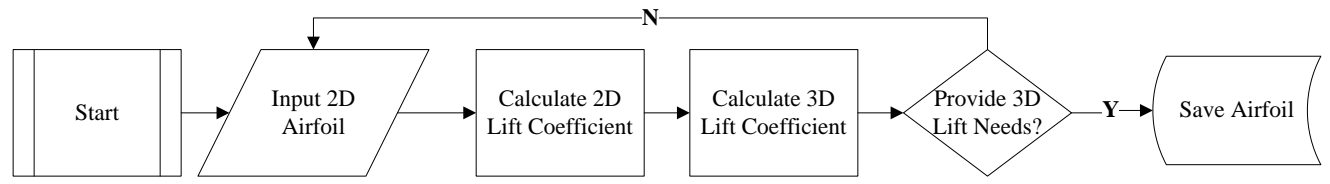

Fig. 8. Chart used to evaluate the airfoil by lift coefficient 
Generally, the pitching moment of wing is related to the pitching moment of airfoil. The following Equation (25)relates these two parameters to aspect ratio and sweep angle.

$\mathrm{C}_{\mathrm{mw}}=\mathrm{C}_{\mathrm{m} \text { airfoil }}\left(\frac{A R \cos \Lambda_{\mathrm{C} / 4}{ }^{2}}{A R+2 \cos \Lambda_{\mathrm{C} / 4}}\right)$

In which $\Lambda_{\mathrm{C} / 4}$ represents the sweep angle of air vehicle atone-fourth of its chord length. With regard to Eq. (17), the pitching moment of airfoil is calculated and then,the following results are obtained.

$$
\mathrm{C}_{\mathrm{mw}}=8.886 \times 10^{-3}
$$

$\mathrm{C}_{\text {mairfoil }}=0.02438$

Next step is aimed at calculating the pitching moment of airfoil required to plan air vehicle via reforming airfoil reflex. Also, with regard to thelimitations of plan such as airfoil thickness, little reformation can beappliedtothe final airfoil geometry. To reduce instability around the pitching axis of airfoil, it is necessary to change the airfoil geometry. Final purpose of this stage is to achieve an airfoil withoptimal performance bychangingthe airfoil reflex which causes its pitching moment to be changed. Also, changing the flap angle and its location changes the pitching moment. Moreover, changing the airfoil pitch leads theaerodynamic coefficients to be changed. It is worthy to noting that pitching moment coefficient increases when flap angle changes to negative values. So effect of thickness on the selected airfoil is valuated and showed in Fig. 10. With regard to drawn profile, and the mission requirements, the raw airfoil thickness is considered as $9 \%$.After that the raw airfoil thickness was selected, next step for adapting airfoil on micro air vehicle is to increase the pitching moment by changing airfoil geometry via flapping. The diagram of this action is shown in $\begin{array}{llll}\text { Fig. } & 11 & \text { and }\end{array}$

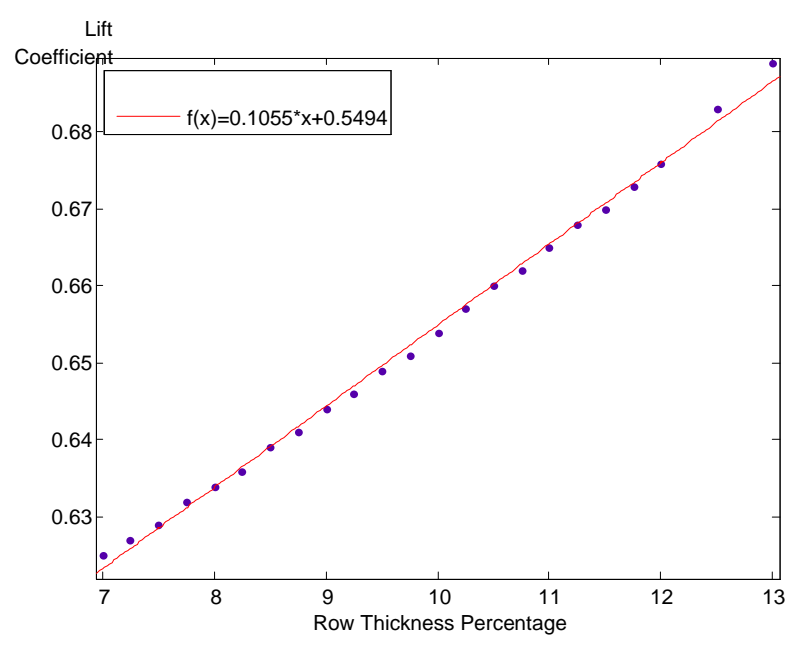

Fig. 10. Lift coefficient vs. row thickness percentage

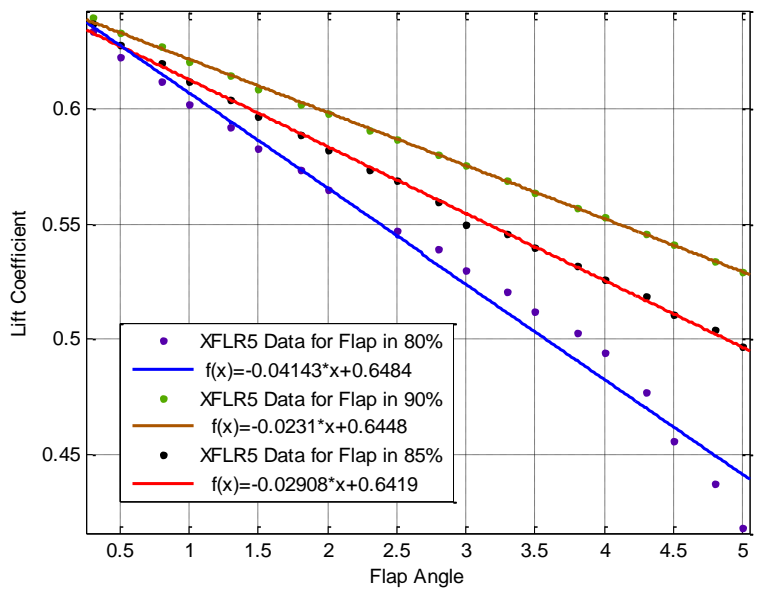

Fig. 11. Effect of flap angle on lift coefficient 


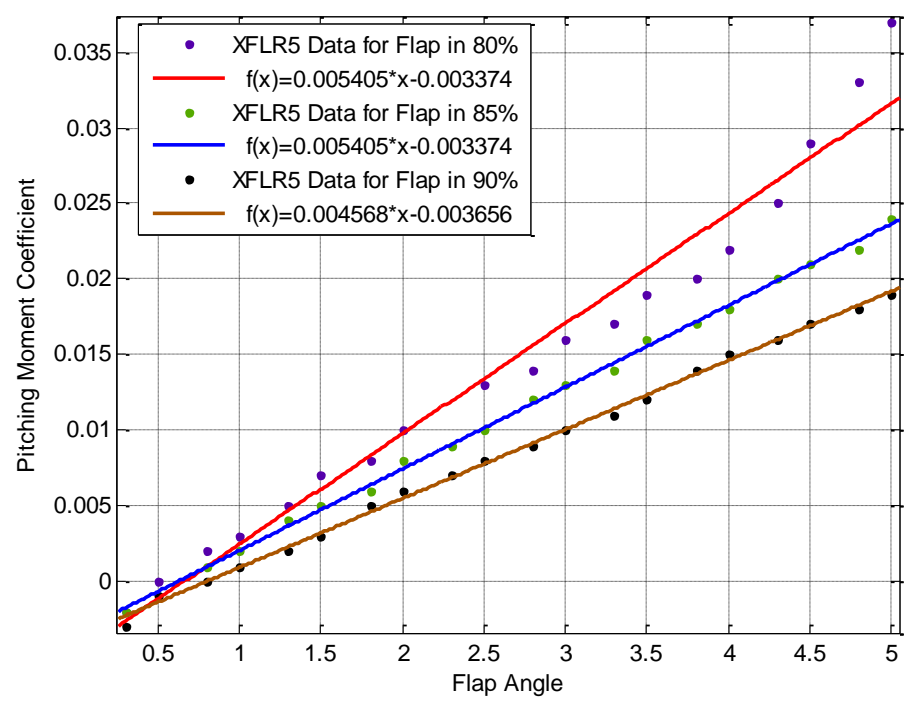

Fig. 12. Effect of flap angle on pitching moment coefficient

From these profiles, it is obvious that increasing the flap angle of tail leads to the pitching moment increment and lift coefficient reduction. As documented from plots, to meet pitching moment at $85 \%$ of Chord line and $50 \%$ of airfoil location, a pitching moment coefficient of 0.02438 is obtained atflap angle of 5 degrees.

After considering the volume coefficient of the vertical tail to be 0.6 and defining the tail place, elevators exact location and their area, the final stepof our design is performed.

Therefore, we can determine the best airfoil according to the MAV performance obtained fromflight test. The related steps are classified in Fig. 13, briefly. It is worthwhile nothing that in the most cases flight test is recommended and wind tunnel test is avoided because there are more differences between wind tunnel test used for low Reynolds numbers and flight test used in turbulent and instable flows according to Watkins researches (Watkins, 2010 ) The result of this designing and ready for flight test is shown in Fig. 14.

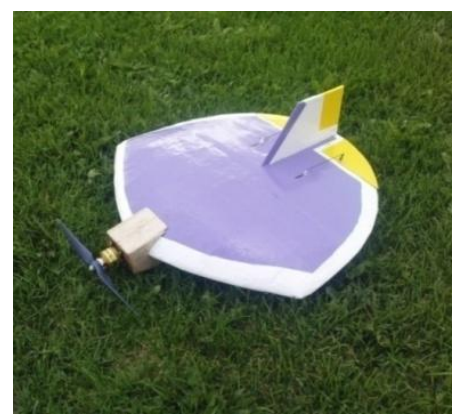

Fig. 13. Ready to fly tests MAV

\section{EXPERIMENTAL FLYING TESTS}

As the final stage of MAV designing some flying test should be carry out. The main goal of the proposed procedure is maneuverability of MAV through the flight. For tracking this goal and showing efficiency of the procedure, a control system was installed on MAV and data of flight was collected.

The main purpose of using a control system during the flight is to stabilize the aircraft after being disturbed from its wing-level equilibrium flight attitude. In this study, by using a Gyro sensor and the control circuit, the longitudinal angle of MAV has been measured. Block diagram of the angle measurement system is shown in Fig. 15.

The main reason of measuring the longitudinal angle is to find out the efficiency of the proposed cycle. The Gyro sensor has been normally placed on the wing with the angle of 4 degrees and this angle has been considered as the level angle. Sensors data has been saved every 0.5 second and plotted for each flight test. Flight tests include hand lunch, increasing altitude, cruse flying and landing. Flight tests has been done in the condition mentioned below:
a) Wind Velocity $=2 \mathrm{~m} / \mathrm{s}$
b) Humidity $=5 \%$
c) Height from the sea $=1400 \mathrm{~m}$

\subsection{Flight Test Analyses}

It is important to mention that in the MAV designed with the proposed procedure, aircraft motor was alimented in 4 degrees with horizontal line. So while aircraft is in normal performance and fly on horizontal line, Gyro sensor shows 4 degrees. 
M. Radmanesh et al. / JAFM, Vol. 7, No. 3, pp. 435-446, 2014.

Therefore, the best longitudinal stability should be

occurs on the mentioned degree.

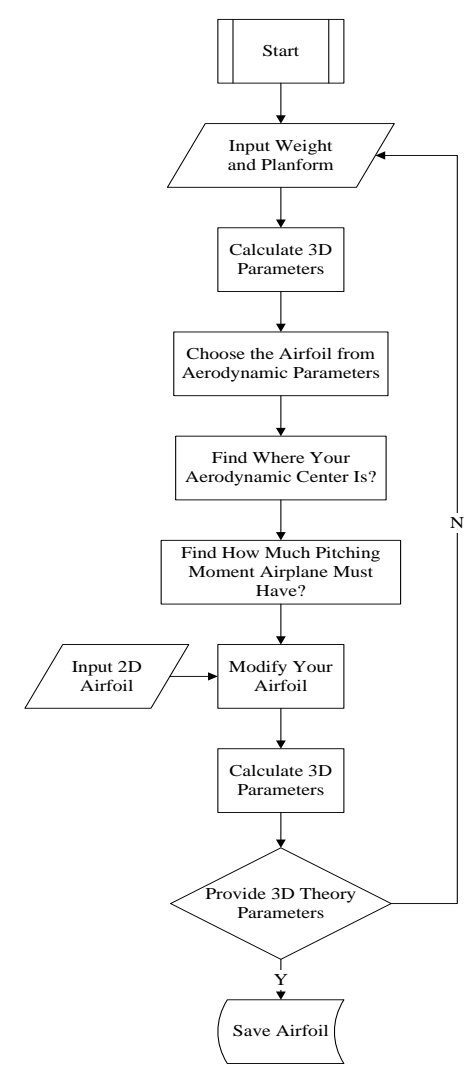

Fig. 14. Designing chart

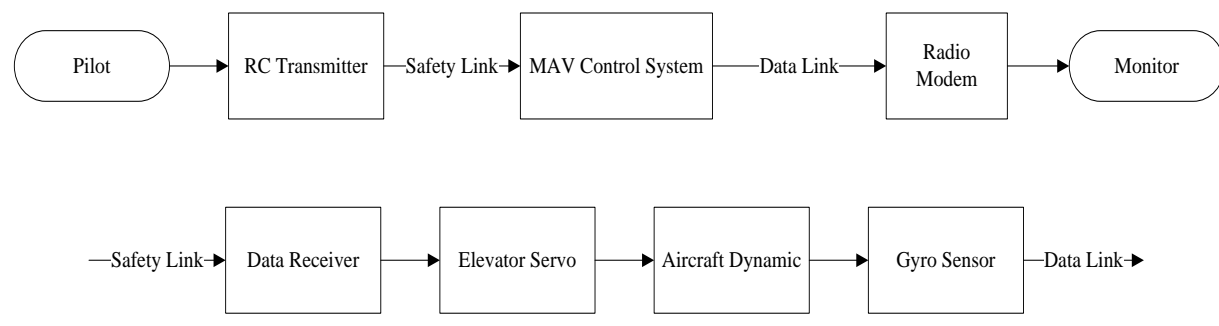

Fig. 15. Block diagram of the angle measurement system

Flight Test No. 1: In this Test the designed MAV has done a nose up flight, which means the MAV has not been stabilized longitudinally. The Longitudinal behavior of MAV has shown in Fig. .16 .

Flight Test No.2: In this test The MAV has shown the behavior as flight test No.1 and it has been plotted in Fig. 17.

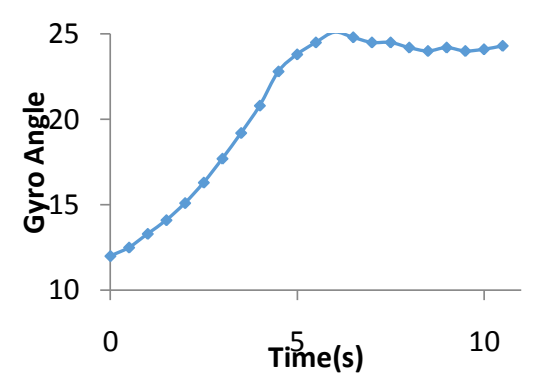

Fig. 16. Flight Test No. 1 


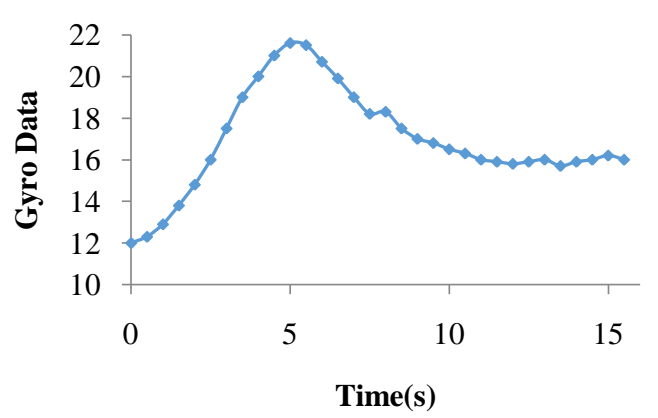

Fig. 17. Flight Test No. 2

The main reason that the MAV behaves Nosed up in the longitudinal axis is that the static margin entered as an input to the cycle, was inappropriate. Flight Test No.3: In these Flight tests the MAV shows an ideal behavior longitudinally. The Gyro sensor data has been plotted in Fig.18. Data has been gained just for the cruise mode.

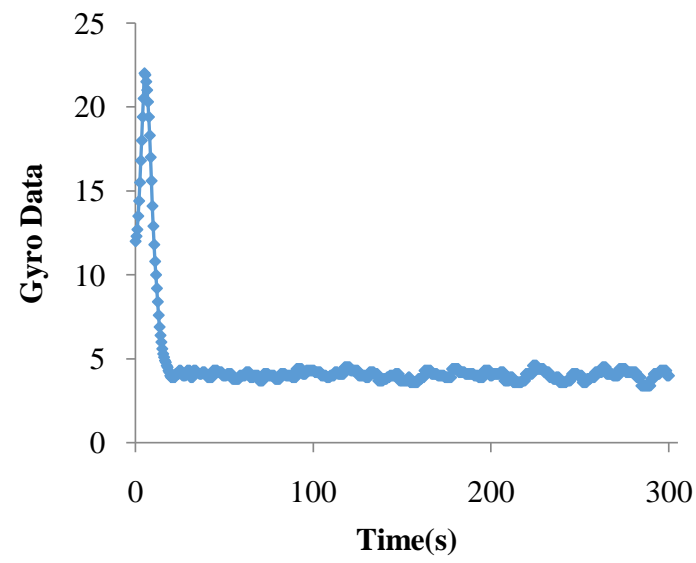

Fig. 18. Flight Test No. 3

In this test, the MAV performed the level flight, perfectly. The flight tests resultsare shown in Table 3. The final manufactured MAVis shown in Fig. 19

Table 3 Flight test results

\begin{tabular}{|c|c|c|c|c|c|c|}
\hline No & $\begin{array}{c}\text { Duration } \\
\text { of test }\end{array}$ & Problem & Correction & Aerodynamics & Stability & Maneuverability \\
\hline 1 & $\begin{array}{c}12 \\
\text { seconds }\end{array}$ & Nose Up Fly & $\begin{array}{l}\text { Moving the center of } \\
\text { gravity forward about } \\
2 \mathrm{~cm}\end{array}$ & - & - & - \\
\hline 2 & $\begin{array}{c}16 \\
\text { seconds }\end{array}$ & Nose Up Fly & $\begin{array}{l}\text { Moving the center of } \\
\text { gravity forward about } \\
1 \mathrm{~cm}\end{array}$ & - & - & - \\
\hline 3 & 5 minutes & $\begin{array}{l}\text { Fly } \\
\text { Normally- } \\
\text { trim of } \\
\text { elevators }\end{array}$ & - & Ok & Ok & - \\
\hline 4 & 6 minutes & $\begin{array}{l}\text { Fly } \\
\text { Normally- } \\
\text { trim of } \\
\text { elevators }\end{array}$ & - & Ok & Ok & Ok \\
\hline
\end{tabular}




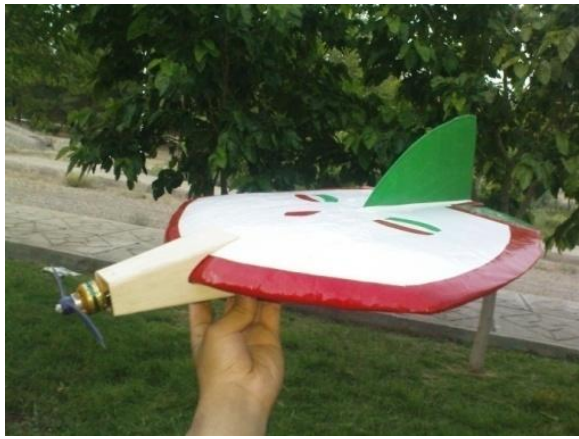

Fig. 19. Output of the designing cycle

\section{CONCLUSION}

The methodology proposed in this research, showed that the time for designing and manufacturing the fixed wing MAV decreases enormously. Also, a novel method waspresented to stabilize the fixed wing MAV longitudinally by changing airfoil geometry. Finally, MH81 was selected as the optimumairfoil.Some changes were applied in row thickness to reach the designing purpose and aerodynamic requirements. Also, the reflex of the airfoil was changed to improve the pitching moment. The research resultswere obtained in $\operatorname{Re}=520000$. The results proved the efficiency of the proposed methodology.

\section{ACKNOWLEDGEMENTS}

This Investigation is sponsored by Isfahan University of Technology and KhodranVafa Co. to attend in IMAV2010 competition held in Germany. The MAV gained the Forth place during the competition.

\section{REFERENCES}

Anderson, D.W., Eberhardt, S., 2009. UnderstandingFlight, Second Edition. McGraw-Hill Companies,Incorporated.

Barnhart, F., Cuipa, M., Stefanik, D., Swick, Z., 2004. Micro-Aerial Vehicle Design with Low Reynolds Number Airfoils. Brigham Yound University.

Cherne, J., Culick, F.E.C., Zell, P., 2000. The AIAA 1903 Wright'Flyer'Project Prior to Full-Scale Tests at NASA Ames Research Center, Proc. of AIAA 38th Aerospace Sciences Meeting.

Corning, G., 1953. Supersonic and subsonic airplane design. Edwards Bros., Ann Arbor, Mich.

Crook, A., Gerritsen, M., Mansour, N., 2002. An experimental investigation of high aspect-ratio rectangular sails, Annual Research Briefs. Center for Turbulence Research, Stanford University.
Deperrois, A., 2010. XFLR5 Analysis of foils and wings operating at low reynolds numbers, 2009. Availiable from: http://xflr5. sourceforge. net/xflr5. htm [Accessed 19 February 2010].

Gallman, J.W., Smith, S.C., Kroo, I.M., 1993. Optimization of joined-wing aircraft. Journal of Aircraft 30, 897-905.

Hassanalian, M., Ashrafizaadeh, M., Ziaei- Rad, S., Radmanesh, M.R., 2012. A new Method for Design of Fixed Wing Micro Air Vehicle, IMAV 2012, Germany.

Liebeck, R.H., 2004. Design of the blended wing body subsonic transport. Journal of Aircraft 41, 10-25.

Mattingly, J.D., Heiser, W.H., Pratt, D.T., 2002. Aircraft Engine Design, Second Edition. Amer Inst of Aeronautics \&.

Mueller, T.J., DeLaurier, J.D., 2003. Aerodynamics of small vehicles. Annual Review of Fluid Mechanics 35, 89-111.

Nicolai, L.M., 1975. Fundamentals of aircraft design. Nicolai : distributed by School of Engineering, University of Dayton.

Obayashi, S., Nakahashi, K., Oyama, A., Yoshino, N., 1998. Design optimization of supersonic wings using evolutionary algorithms, Proc. 4th ECCOMAS Computational Fluid Dynamics Conf, 575-579.

Obayashi, S., Sasaki, D., Takeguchi, Y., Hirose, N., 2000. Multiobjective evolutionary computation for supersonic wing-shape optimization. Evolutionary Computation, IEEE Transactions on 4, 182-187.

Radmanesh, M.R., Hassanalian, M., Feghhi, S.A., NiliAhmadabadi, M., 2012. Numerical Investigation of Azarakhsh MAV, IMAV2012, Germany.

Raymer, D.P., 2012. Aircraft Design: A Conceptual Approach. Amer Inst of Aeronautics \&.

Recktenwald, B.D., Crouse, G.L., Ahmed, A., 2010. Experimental Investigation of a CircularPlanform Concept Aircraft. Journal of Aircraft 47, 887-894.

Roskam, J., 1985. Airplane Design: Preliminary configuration design and integration of the propulsion system. Design Analysis \& Research.

Stinton, D., 1998. The anatomy of the airplane. American Institute of Aeronautics and Astronautics. 
M. Radmanesh et al. / JAFM, Vol. 7, No. 3, pp. 435-446, 2014.

Torenbeek, E., 1982. Synthesis of Subsonic Airplane Design: An Introduction to the Preliminary Design of Subsonic General Aviation and Transport Aircraft, with Emphasis on Layout, Aerodynamic Design, Propulsion and Performance. Springer.

Torres, G.E., Mueller, T.J., 2004. Low-aspect-ratio wing aerodynamics at low Reynolds numbers. AIAA journal 42, 865-873.

Wakayama, S., Kroo, I., 1995. Subsonic wing planform design using multidisciplinary optimization. Journal of Aircraft 32, 746-753.
Watkins, S., Abdulrahim, M., Marino, M., Ravi, S., . Flight Testing of a Fixed Wing MAV in Turbulence with Open and Closed Loop Control, IMAV 2010, Germany.

Whitford, R., 1987. Design for air combat. Jane's.

Wood, K.D., 1968. Aerospace Vehicle Design, Volume I, Aircraft Design, 3 ed. Johnson Publishing, Boulder, Colorado.

Zhang, X.Q., Tian, L., 2007. Three-Dimensional Simulation of Micro Air Vehicles with LowAspect-Ratio Wings. Key Engineering Materials 339, 377-381. 